exacerbations, and primary and secondary care contacts were re-analysed using the same generalised linear models as for the original SLS study but with the addition of a treatment by deprivation quintile interaction term.

Results Participants in the more deprived categories were more likely to be younger, more likely to smoke and slightly more obese but were balanced between genders. There was no association with deprivation and withdrawal rates or with adherence (proportion of days covered). An additional post-hoc analysis demonstrated that Deprivation was associated with more primary and secondary care contacts and higher costs (Table). Deprivation did not interact with the effect of FF/VI $\mathrm{v}$ UC on the primary outcome measure (annual rate of moderate to severe exacerbations) or health care contacts or safety endpoints including all-cause mortality and pneumonia.

Conclusions The unique design of SLS allowed the RCT to be conducted in a deprived population who would normally be excluded from RCTs. Higher deprivation was not associated with higher drop-out rates or poor adherence, but was associated with higher rates of smoking, obesity and co-morbidities and higher health care consumption and costs. With its once daily dosage and ease of use FF/VI had potential to benefit people with poor adherence and preferentially benefit deprived populations, however deprivation scores did not moderate the effect of FF/VI $\mathrm{v}$ UC in primary, secondary or safety outcomes.

Funding GSK (HZC115151/NCT01551758).

Please refer to page A258 for declarations of interest in relation to abstract P27.

Abstract P27 Table 1 Deprivation and primary and secondary care contacts and total COPD costs (medication including study medications and healthcare costs for COPD)

\begin{tabular}{|c|c|c|c|c|}
\hline \multirow[t]{2}{*}{ Deprivation Quintile } & \multicolumn{2}{|c|}{$\begin{array}{l}\text { Mean (SD) Number of } \\
\text { Healthcare Contacts }\end{array}$} & \multicolumn{2}{|c|}{$\begin{array}{l}\text { COPD Care Costs Per } \\
\text { Subject } \\
\text { Geometric Mean } \\
\text { (Geometric SD) }\end{array}$} \\
\hline & $\mathrm{FF} / \mathrm{VI}$ & UC & $\mathrm{FF} / \mathrm{VI}$ & UC \\
\hline 1 (most deprived) & $32.0(23.38)$ & $29.4(22.24)$ & $842.1(2.33)$ & $981.4(2.08)$ \\
\hline 2 & $29.7(21.77)$ & $28.4(21.84)$ & $742.5(2.11)$ & $984.1(2.12)$ \\
\hline 3 & $29.9(19.02)$ & $28.4(20.32)$ & $819.0(1.96)$ & $955.2(2.13)$ \\
\hline 4 & $29.2(19.26)$ & $27.4(18.59)$ & $730.7(1.89)$ & $894.8(2.02)$ \\
\hline 5 (least deprived) & $27.5(22.40)$ & $21.3(14.89)$ & $743.4(2.03)$ & $823.6(1.84)$ \\
\hline
\end{tabular}

Note: $\mathrm{SD}=$ Standard deviation

\section{P28 THE USE OF A NOVEL CASE-FINDING ALGORITHM IN THE IDENTIFICATION OF CHRONIC OBSTRUCTIVE PULMONARY DISEASE (COPD) PATIENTS IN PRIMARY CARE - EARLY RESULTS OF THE ASSIST STUDY}

${ }^{1} \mathrm{C}$ Healy, ${ }^{2} \mathrm{~A}$ Hicks, ${ }^{2} \mathrm{~K}$ Gillett, ${ }^{2} \mathrm{E}$ Ray, ${ }^{2} \mathrm{H}$ Kruk, ${ }^{2} \mathrm{M}$ North, ${ }^{1} \mathrm{C}$ Newell, ${ }^{3} \mathrm{DM}$ Thomas, ${ }^{2} \mathrm{~T}$ Wilkinson. ${ }^{1}$ University Hospital Southampton, Southampton, UK; ${ }^{2}$ National Institute for Health Research (NIHR) Collaboration for Leadership in Applied Health Research and Care Wessex, Southampton, UK; ${ }^{3}$ University of Southampton, Romsey, UK

\subsection{6/thoraxjnl-2017-210983.170}

Introduction In the UK around 900000 people have a diagnosis of COPD. Despite its high prevalence under-diagnosis is common in primary care with an additional 2 million cases suggested. Opportunities for early diagnosis and intervention are frequently missed. The best strategy for targeted case finding is unclear.

Methods The ASSIST study (Rec: 15/5C/598580) used a previously trialled, computerised case-finding algorithm, ${ }^{1}$ applied remotely into primary care systems for case finding. It applies weighted risk factors as search terms (e.g., smoking history, history of breathlessness, use of inhalers and antibiotics). To date, eight GP Practices, serving 101754 patients in Hampshire, UK have been screened (figure 1). The algorithm identified 1725 possible undiagnosed patients; 506 were excluded by their GP and study team. The remaining 1216 were invited for an hour long assessment with a specialist respiratory nurse at their surgery, which included medical and smoking history, vital signs and spirometry.

Results To date, response rates are 18\% (222). Of respondees, 178 were eligible and attended for screening (Male 55\%, mean age 64.1, SD 5.5, age range 48-72). 27\% (48) had obstructive spirometry $\left(\mathrm{FEV}_{1} / \mathrm{FVC}<0.7\right)$ without reversibility. $40 \%$ (19) of these had moderate obstruction $\left(\mathrm{FEV}_{1} 50 \%-79 \%\right.$ predicted) (mean $\mathrm{FEV}_{1} \%$ predicted $88 \%$, SD 15.6). Of those with obstructive lung function, 46\% (22) have a MRC score of $\geq 2 \%$ and $8 \%$ (4) had exacerbations within the previous year. The mean pack year history was 31.9/34.9 (SD 24/108) for obstructed vs. non-obstructed.

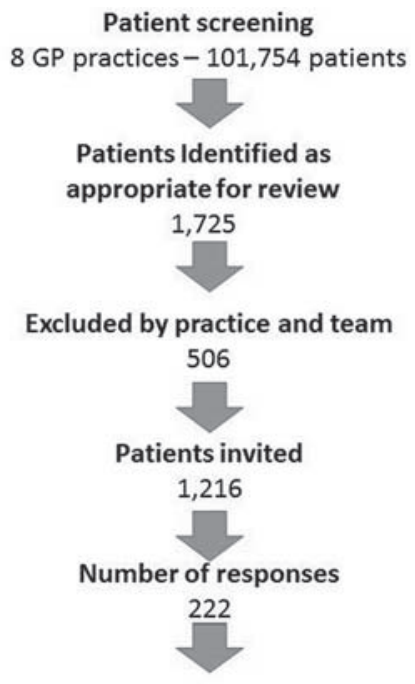

Recruited to the study 178

Obstruction based on FEV1/FVC ratio $<0.70$

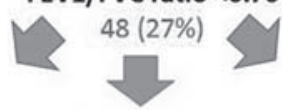

- $1: 26$

- 2:17

- 3:4

- $4: 1$

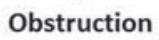

FEV 1

based on LLN

$25(15 \%)$

- $\geq 80 \%: 29$

- $50-79 \%: 19$ 
burden with $40 \%$ having moderate airflow obstruction and $46 \%$ having quality of life impairment. We are continuing to recruit further practices. Subsequent work will examine whether using this algorithm Results in earlier identification of COPD in a cost-effective manner and an improvement in quality of life for patients.

\section{REFERENCE}

1. Jordan PPA et al. Targeted case-finding for chronic obstructive pulmonary disease versus routine practice in primary care (TargetCOPD): A cluster-randomised controlled trial 2016. http://www.thelancet.com/journals/lanres/article/PIIS2213-2600 (16)30149-7/fulltext

\section{P29 CLINICAL CHARACTERISTICS AND MANAGEMENT OF PATIENTS WITH AN INACCURATE DIAGNOSIS OF CHRONIC OBSTRUCTIVE PULMONARY DISEASE (COPD) IN PRIMARY CARE; RESULTS FROM THE WELSH NATIONAL COPD PRIMARY CARE AUDIT}

${ }^{1} \mathrm{M}$ Fisk, ${ }^{2} \mathrm{~V}$ McMillan, ${ }^{3} \mathrm{~J}$ Brown, ${ }^{2} \mathrm{~J}$ Holzhauer-Barrie, ${ }^{2} \mathrm{MS}$ Khan, ${ }^{4} \mathrm{~N}$ Baxter, ${ }^{5} \mathrm{CM}$ Roberts. ${ }^{1}$ Barts Health NHS Foundation Trust, London, UK; ${ }^{2}$ Royal College of Physicians, London, UK; ${ }^{3}$ Royal Free NHS Foundation Trust, London, UK; ${ }^{4}$ Royal College of Physicians and NHS Southwark CCG, London, UK; ${ }^{5}$ Clinical Effectiveness and Evaluation Unit, Royal College of Physicians and Queen Mary University of London, London, UK

\subsection{6/thoraxjnl-2017-210983.171}

Introduction Spirometry is required to make a clinical diagnosis of COPD, confirming persistent airflow limitation. However, studies suggest that making the correct diagnosis of COPD in primary care can be challenging. We sought to evaluate the clinical characteristics and management in primary care of patients registered with COPD but with incompatible spirometry, compared to patients with spirometry compatible with COPD.

Methods This analysis used data from the Welsh national COPD primary care audit, which prospectively collected data of patients, registered with COPD from $61 \%$ of GP practices in Wales covering January 2014-March 2015. Patients registered with COPD but with incompatible spirometry (postbronchodilator forced expiratory lung volume in $1 \mathrm{~s}\left(\mathrm{FEV}_{1}\right) /$ forced vital capacity (FVC) $\geq 0.70$ ) were compared to COPD patients with compatible spirometry $\left(\mathrm{FEV}_{1} / \mathrm{FVC}<0.70\right)$.

Results In total, 8957 patients registered with COPD were evaluated, 2255 (25\%) had incompatible spirometry, 6702 had compatible spirometry. There were no differences in age (71 \pm 10 vs $70 \pm 11$ years) or asthma co-diagnosis $(13.1 \%$ vs $13.1 \%$ ), between these respective groups, but patients with incompatible spirometry had a higher body mass index $(29.41$ \pm 6.69 vs $\left.27.04 \pm 5.94 \mathrm{~kg} / \mathrm{m}^{2}, \mathrm{p}<0.001\right)$ and were more likely female $(48.8 \%$ vs $45.6 \%, p=0.009)$. There were also differences in smoking status $(14.3 \%$ vs $8.6 \%$ never-smokers, $\mathrm{p}<0.001)$, and spirometry $\left[\left(\mathrm{FEV}_{1} / \mathrm{FVC}: 0.78\right.\right.$ vs 0.55 , $\mathrm{p}<0.001), \quad\left(\mathrm{FEV}_{1} \%\right.$ predicted: $\quad 72 \pm 18 \%$ vs $58 \pm 18 \%$, $\mathrm{p}<0.001$ )], but similar levels of breathlessness (MRC: 2.52 \pm 0.94 vs $2.55 \pm 0.98, \quad \mathrm{p}=0.17)$ and exacerbation frequency $(6.86 \pm 7.5$ vs $7.3 \pm 8.8, p=0.05)$. Despite incompatible spirometry, $30.4 \%$ of these patients received long acting beta agonist (LABA) therapy, $51.7 \%$ inhaled corticosteroids (ICS), $73 \%$ long acting muscarinic antagonist (LAMA), and 74.6\% combined inhaled LABA/ICS therapy. Furthermore, there were no differences for LAMA $(73 \%$ vs $73 \%, \mathrm{p}=0.99)$ or LABA/ICS
$(76.7 \%$ vs $74.3 \%, p=0.37)$ use in patients with incompatible spirometry with or without a diagnosis of asthma respectively, although more patients with asthma received LABA $(38.9 \%$ vs $29.1 \%, \mathrm{p}=0.001)$ and ICS $(57.1 \%$ vs $50.8 \%, \mathrm{p}=0.05)$ therapies.

Conclusions Patients without persistent airflow limitation diagnosed incorrectly with COPD, are symptomatic and receiving inappropriate pharmacological therapies. These data suggest that a breathlessness pathway may be helpful to aid diagnosis and management of such patients seen in primary care.

\section{P30 A SERVICE EVALUATION TO ASSESS THE ACCURACY OF THE GOLD STANDARD FRAMEWORK PROACTIVE INDICATOR GUIDANCE (GSF PIG) IN PREDICTING 12 MONTH MORTALITY IN PATIENTS WITH A DIAGNOSIS WITH CHRONIC OBSTRUCTIVE PULMONARY DISEASE}

${ }^{1} S$ Pilsworth, ${ }^{2} \mathrm{~J}$ Crane, ${ }^{1} \mathrm{D}$ Wat, 'S Sibley, 'M Shaw. 'Liverpool Heart and Chest Hospital, Liverpool, UK; ${ }^{2}$ University of Liverpool, Liverpool, UK

\subsection{6/thoraxjnl-2017-210983.172}

Background Patients with a diagnosis of chronic obstructive pulmonary disease (COPD) have a limited life expectancy and poorer quality of life, which can manifest with a high symptom burden especially towards the end of life. The benefits of offering palliative care to this patient group is well known but they frequently have poorer outcomes and worse access to palliative care services and symptom management. Knowing when to instigate appropriate palliative care in this group is challenging due to prognostic uncertainty. The Gold Standard Framework (GSF) is recommended for use in primary care settings with this patient group to predict 12 month mortality, it is stated to be accurate in $70 \%$ of cases, however there is little evidence to support this. This study aims to evaluate the effectiveness of this tool in predicting 12 month mortality in patients with a diagnosis of COPD.

Method Retrospective data from one community respiratory service in the North West of England, was collected between January 2013 and January 2016, of patient's deemed to be entering the last 12 months of life by triggering the GSF tool. The length of time on the palliative register until either death or January 2107, when data analysis commenced, was reviewed. All the data utilised in this evaluation was routinely collected by the service.

Results Of the 448 patients included in this evaluation only 122 died within 12 months, meaning the GSF was accurate in predicting 12 month mortality in $27 \%$ of cases included in this review $(n=448)$. Sub group analysis of the different GSF triggers and routinely collected data hints at the possible importance in pulmonary rehabilitation to reduce mortality (OR 0.1079 (95\%CI $0.0674-0.1726 \mathrm{p}<0.0001)$ ) with gait speed potentially being an early prognostic indicator ( $\mathrm{p}$-value 0.008).

Conclusion This study suggests that in this cohort the GSF PIG is not an accurate predictor of 12 month mortality in patients with a diagnosis of COPD to the suggested $70 \%$. It does hint at the importance of PR and gait speed in prognostication. 